\title{
Por uma Visão Crítica nos Estudos Turísticos ${ }^{12}$
}

\author{
For a Critical Vision of Tourism Studies
}

Por Una Visión Critica en los Estudios Turisticos

\author{
Alexandre Panosso Netto ${ }^{3}$ \\ Félix Tomillo Noguero ${ }^{4}$ \\ Margret Jäger ${ }^{5}$
}

\begin{abstract}
Resumo
O presente artigo parte da observação de que os estudos turísticos estão passando por uma revisão das teorias desenvolvidas até o momento e das novas propostas que têm sido criadas nos últimos anos. A pesquisa em turismo ainda não conseguiu construir marcos conceituais estáveis e há carência de continuidade e complementaridade entre os estudos realizados, sendo estes, em grande maioria, com viés positivista. Isso ocorre, entre outros motivos, pelo desconhecimento de estudos realizados nos primórdios do desenvolvimento do turismo enquanto objeto de investigação. Além disso, há o desprezo quase que generalizado, por parte da corrente intelectual dominante, por tudo o que não seja publicado em língua inglesa. Essa crise dos estudos do turismo é reflexo de uma crise maior, que se manifesta em quatro aspectos principais: 1) a crise da universidade, 2) a crise na filosofia, 3) a crise dos valores culturais, humanos, morais e éticos e 4) a crise dos valores históricos. Os autores concluem que para construir tal conhecimento crítico nos estudos turísticos, será necessário basear-se nos valores e alicerces da Filosofia e da Epistemologia, caso contrário o conhecimento pouco
\end{abstract}

\footnotetext{
${ }^{1} \mathrm{O}$ presente texto é fruto dos resultados preliminares do projeto de pesquisa apoiado pela Fundação de Amparo à Pesquisa do Estado de São Paulo (FAPESP), coordenado por Alexandre Panosso Netto, com participação de Félix Tomillo Noguero, intitulado "Fundamentos científicos das teorias em turismo: uma análise histórica". As demais autoras do presente artigo, em etapas diversas, colaboraram com a investigação.

2 Trabalho apresentado no I Seminário Internacional de Estudos Críticos em Turismo realizado nos dias 24 e 25 de março de 2011, organizado pelo grupo de pesquisa Estudos Críticos em Turismo ESCRITUR/UFRN/CNPq.

${ }^{3}$ Professor Doutor na Escola de Artes, Ciências e Humanidades da Universidade de São Paulo (EACH-USP). Membro do grupo de pesquisa Estudos Críticos em Turismo (ESCRITUR), sediado na Universidade Federal do Rio Grande no Norte (UFRN) e do grupo Pesquisa, Educação e Formação Profissional em Turismo e Hospitalidade, sediado na EACH-USP. E-mail: panosso@usp.br.

${ }^{4}$ Professor doutor na Universidad Antonio de Nebrija (Madrid-Espanha) e na Universidad Europea Miguel de Cervantes (Valladolid-Espanha). Membro do grupo de pesquisa Estudos Críticos em Turismo (ESCRITUR), sediado na UFRN. E-mail: felixtomillo@ono.com.

${ }^{5}$ Doutora Senior Research Scientist na Private Universität für Gesundheitswissenschaften Medizinische Informatik und Technik (UMIT), Viena (Áustria). E-mail: margret.jaeger@umit.at.
} 
avançará e ficará limitado às vontades e desejos de grupos "proprietários" do conhecimento turístico.

Palavras-chave: turismo; crise; estudos críticos; filosofia; epistemologia.

\begin{abstract}
The starting point of this paper is the observation that studies in tourism have been through a review of the theories developed so far and that new proposals have emerged in recent years. Research in tourism has yet to be able to build steady conceptual boundaries and there is a lack of continuity and complementarity among studies, which bring mostly the positivist perspective. That happens, among other reasons, due to the unawareness of studies undertook in the early ages of tourism as an object of investigation. Furthermore, the majority of the intellectual mainstream disregards everything not published in English. This crisis in tourism studies is itself a reflex of a larger crisis manifested in for main aspects: 1) the crisis of universities, 2) the crisis in Philosophy, 3) the crisis of cultural, human, moral and ethical values, and 4) the crisis of historical values. The authors conclude that, in order to build such a critical knowledge in tourism studies, it is necessary to make use of values and principles from Philosophy and Epistemology, otherwise there will be no advances and tourism knowledge will be kept restrained by those who "own" it.
\end{abstract}

Keywords: tourism; crisis; critical studies; philosophy; epistemology.

\title{
Resumen
}

El presente artículo parte de la observación de que los estudios turísticos están pasando por una revisión de las teorías desarrolladas hasta ahora y de las nuevas propuestas que han surgido en los últimos años. La investigación en turismo todavía no consiguió construir marcos conceptuales estables y hay una falta de continuidad y complementariedad entre los estudios realizados, teniendo una gran mayoría de ellos un sesgo positivista. Eso ocurre, entre otros motivos, por el desconocimiento de los estudios realizados en los inicios del desenvolvimiento del turismo en cuanto objeto de investigación. Además, existe el desprecio cuasi generalizado, por parte de la corriente intelectual dominante, por todo lo que no se publique en inglés. Esta crisis de los estudios de turismo constituye el reflejo de una crisis mayor, que se manifiesta en cuatro aspectos principales: 1) La crisis de la universidad. 2) La crisis en la filosofía. 3) La crisis de los valores culturales, humanos, morales y éticos. 4) La crisis de los valores históricos. Los autores concluyen que, para construir tal conocimiento crítico en los estudios turísticos, será necesario basarse en los valores y fundamentos de la Filosofía y de la Epistemología; en caso contrario, el conocimiento avanzará poco y se limitará a las voluntades y deseos de los grupos "propietarios" del conocimiento turístico.

Palabras clave: turismo; crisis; estudios críticos; filosofia; epistemología. 


\section{TURISMO EM ANÁLISE}

\section{Introdução}

O presente artigo parte da observação de que os estudos turísticos estão passando por uma revisão das teorias até então desenvolvidas e novas propostas têm sido criadas nos últimos anos. Tal fato pode ser facilmente verificado nos trabalhos de inúmeros autores, entre eles MacCannell (2011), Tribe (2007, 2010), Holden (2011), Ateljevic, Pritchard e Morgan (2007), Conde Gaxiola (2008), Castillo Nechar e Lozano Cortés (2006).

Para a compreensão do complexo fenômeno turístico, ou ao menos a tentativa de sua compreensão, análises positivistas, sistêmicas, fenomenológicas, marxistas, hermenêuticas, anarquistas, entre outras, têm sido construídas. Conceitos filosóficos, sociais e antropológicos, tais como, fenomenologia, pós-modernidade, hipermodernidade, mobilidade, são revisados e atualizados, gerando uma profusão de novos conhecimentos e novas abordagens teóricas, e que podem confundir até o mais experiente pesquisador.

Porém, nem toda abordagem produz conhecimentos sólidos - e com um mínimo de "vida útil" - que servem de base para novas pesquisas. Concordamos, neste ponto, com MacCannell (2011), quando afirma que "a pesquisa em turismo não conseguiu construir marcos conceituais estáveis" (p.35) e que "nenhuma teoria é tão avançada para ter o poder de situar e dar sentido e significado a um crescente número de observações" (p.36).

A análise tradicional do turismo, predominantemente positivista, está focada nos impactos do turismo, nos turistas, nas relações entre turistas e pessoas do local, no funcionamento do "sistema turístico" e nas consequências do fenômeno (APOSTOLOPOULOS, 2005; CASTILLO NECHAR e PANOSSO NETTO, 2010). Poucas vezes o valor do turismo é discutido; o seu significado desde tempos imemoráveis e para a atualidade; a necessidade dos deslocamentos; o que significa estar em viagem e; qual o significado das viagens. Essas são questões fundamentais para a visão crítica da área, porém ainda não são abordadas com a seriedade necessária.

Outro problema identificado é a centralização, na atualidade, das publicações em turismo em idioma inglês e que os pesquisadores que têm esse idioma como materno, desconsideram publicações em outros idiomas, com algumas poucas exceções. Sobre isso, Dann e Parrinello 


\section{TURISMO EM ANÁLISE}

(2009) e Dann (2011), expuseram, de forma veemente, este viés linguístico e científico caracterizado pela hegemonia da lógica anglo-saxônica.

Não se trata de negar a importância da produção acadêmico-científica publicada em inglês como ferramenta de divulgação da ciência, mas sim de rejeitar a visão de que somente publicações neste idioma são importantes e válidas; ou que publicações em inglês seriam superiores em qualidade às publicações em outros idiomas. Além disso, conforme apontam Panosso Netto e Tomillo Noguero (2011, inédito), o idioma "mãe" do conhecimento turístico, ao menos no mundo Ocidental, é o alemão, ao qual se somam importantes estudos de fins do século XIX publicados principalmente em polonês, francês, espanhol e italiano. O inglês, portanto, não está substancialmente representado na origem dos primeiros conhecimentos teóricos do turismo.

A omissão dos autores e obras não anglófonas não é uma constante histórica, mas sim algo esporádico, próprio de nosso tempo ${ }^{6}$. A geração intelectual de fins do século XIX e princípios do $\mathrm{XX}$, tanto a que escrevia em inglês, como a que utilizava outras línguas europeias, fez frente a uma das fases mais cruciais da história ocidental (aquilo que os anglo-saxões costumam chamar de turning point), com uma reorientação crítica e criativa do pensamento, que produziu um novo mundo científico e filosófico que ainda hoje segue tomando-se, em certas ocasiões, como referência. Foi a resposta a uma crise que afetava ao mesmo tempo a todos os campos da investigação. Naqueles dias, homens ilustrados desafiavam o sentimento de decadência da civilização ocidental e geravam a racionalidade moderna que levou da crise à revolução dos fundamentos, ou seja, a destruição das pedras angulares da epistemologia que haviam construído a episteme clássica: von Ranke, Marx, Mendel, Taine, Pasteur, Burckhardt, Nietzsche, Mommsen, Boltzmann, Dilthey, Koch, Mendeléyev, Poincaré, Hittorf, Dedekind, Mach, Durkheim, Weber, Kropotkin, Pareto, Röntgen, Pirenne, Ramón e Cajal, Marie Curie, Spengler, Husserl, Freud, Gaetano Mosca, Hazard, Huizinga, Planck, Einstein, Pannekoek, Bohr, Born, Schrödinger, Heisenberg, Camus, Adorno, Heidegger, Lacan, von Mises, von Hayek e demais membros de uma plêiade que não tinha o inglês como língua materna.

\footnotetext{
${ }^{6}$ Consideramos que os anglófonos tendem a redefinir a realidade, adaptando-a a seus interesses e vontades. Segundo a redefinição dos EUA, eles são mais que uma parte da América do Norte, são "toda a América". Os EUA vêm utilizando o nome "América" e, com isso, arrebatando a condição de americanos dos demais países e cidadãos do continente de Colombo.
} 
Por sua vez, no lado dos anglófonos, distintos sábios fizeram o mesmo, e não tiveram inconveniente algum em beber nas fontes alemãs, francesas, italianas, espanholas, portuguesas, polonesas, russas, neerlandesas entre outras. A literatura científica e tecnológica em inglês, do final do século XIX e início do XX, acumula um acervo menos numeroso. Alguns inventores não publicaram, como é caso de Morse, Edison, Westinghouse, Bel e Eastman. Por isso, a lista dos autores de publicações importantes é menor: Darwin, Lord Kelvin, F. W. Aston, E. B. Titchener, J. B. Watson, B. F. Skinner, W. E. B. du Bois, G. H. Mead, H. G. Blumer, Parsons, Boas (germano-estadounidense), J. R. Oppenheimer, Tansley, C. D. Anderson, R. E. Franklin, E. O. Lawrence, Keynes, Friedman, Pauling e outros poucos mais.

$\mathrm{Na}$ atualidade, a negligência do anglo-saxão vai tão longe, ao extremo dos estudos estarem mais focados aos países anglo-saxões (essa parece ser a regra, mas há grupos, universidades e pesquisadores isolados que pesquisam destinos chamados "periféricos", tais como Tailândia, Costa Rica, México, Marrocos, Egito e Vietnã) e atribuir-se inovações e descobrimentos que outros científicos ou filósofos já alcançaram antes. Esta atitude será mantida dentro de 20 ou 30 anos? Estaria o chinês a ponto de converter-se em língua franca no prazo de uma ou duas gerações? Continuarão os países "colonizados" incorporando anglicismos, danosos para a linguagem, sem que sejam absolutamente necessários? Entre os não anglófonos cresce o número de jornalistas, literatos e cientistas que incorporam, desnecessariamente, termos ingleses, por terem caído na estupefação, ou para presumir ou vangloria-se de estar "ao dia", sem perceberem que isso empobrece a sua língua materna. Como exemplo está a última novidade: à crise econômica internacional, à moratória, à suspensão dos pagamentos internos e externos, à quebra, que insistem em chamar de "default". Mas isso não é o mais drástico, pois cada vez mais a degeneração não somente afeta o léxico, mas também a sintaxes, com o qual pode-se estar arruinando a base da gramática nativa; assim, o modo subjuntivo faz tempo que entrou em vias de extinção em alguns idiomas, como por exemplo o espanhol, e o mesmo está ocorrendo com o modo condicional em francês, italiano e novamente no espanhol.

As considerações acima trazem o entendimento de que algumas das teorias de turismo, que são consideradas criação do mundo anglo-saxão após a década de 1970, têm, na realidade, seu 
nascimento em outros idiomas. Suas origens estão em autores alemães, suíços, austríacos, franceses, italianos, neerlandeses, bielorrussos da antiga União das Repúblicas Socialistas Soviéticas (URSS) e outros que publicaram primeiro em suas línguas maternas. Ilustrando essa explicação, está o Quadro 1, que apresenta: a) alguns temas da sociologia do turismo; b) autores considerados como "criadores da teoria", ou seus maiores divulgadores, e; c) autores que primeiro escreveram sobre o assunto. O quadro foi inspirado na discussão feita por Dann (2011), e aqui segue ampliado e modificado.

Quadro 1- Origens de algumas teorias de turismo

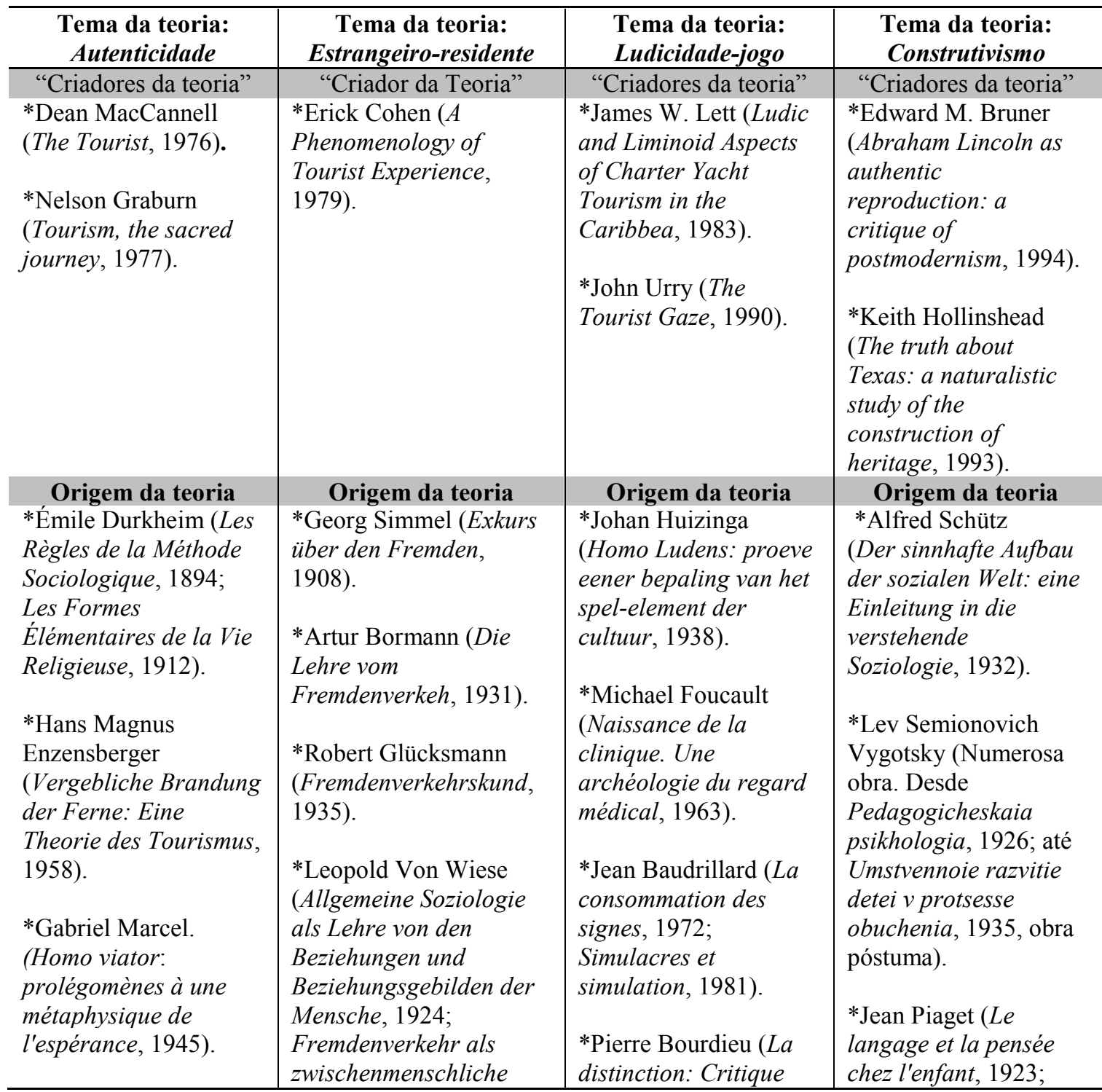




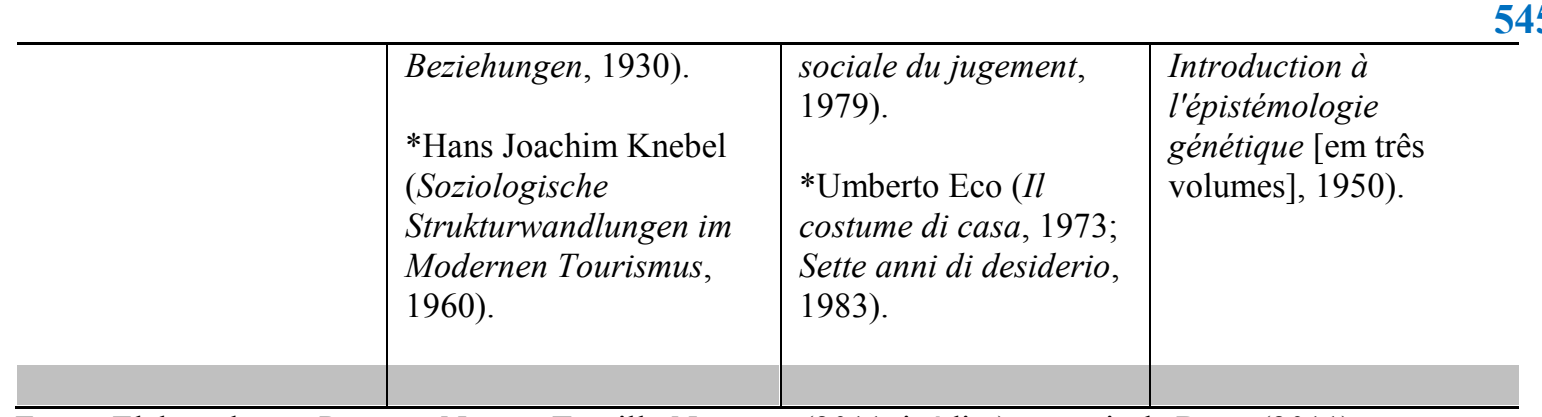

Fonte: Elaborado por Panosso Netto e Tomillo Noguero (2011, inédito), a partir de Dann (2011).

Outra crítica geral é sobre os estudos de caso. Desde os últimos 25 anos, a investigação turística tem tendência - ao menos na literatura ocidental - a centrar-se de modo preferencial nos aspectos particulares de uma realidade determinada temporal e espacialmente, o que se plasma na abundância de estudos de caso, em forma de monografia ou em forma de publicações mistas. Os estudos de casos em si mesmos são ferramentas da construção do conhecimento e, portanto, não devem ser em princípio rejeitados, senão justamente o contrário. Mas existem investigadores que convertem seus estudos de caso não em um método de investigação que recorre à experiência como via para a transmissão do conhecimento, que é o que são realmente, senão em investigação mesma, transcendendo assim do que este é intrinsecamente. Ou seja, é atribuído ao estudo de caso uma característica e um papel que ele não tem.

Mas neste tema há outra disfunção quando estudiosos de casos, alicerçados em posições empiristas (que são contrárias a toda não apriorística e a todo conceito universal e absoluto, motivo pelo qual nunca conduzem a uma definição coerente), tentam elaborar teoria ou conhecimento especulativos considerados com independência de sua aplicação prática, ou formular leis que sirvam para relacionar uma ordem concreta de fenômenos, ou aplicar suas conclusões a toda turismologia ou teorologia ${ }^{7}$. Tomillo Noguero (2008) opina que esse desvio nos objetivos ou fins científicos dos estudos de casos mencionados, oferecem conotações com o relativismo, filosofia imperante contra a que se lançou valentemente o metodólogo Mario Bunge. Hoje são muitos os cientistas e homens simples que percebem, ao contrário de Bunge,

\footnotetext{
${ }^{7}$ Stafford (1985), para quem o termo teorologia designa a ciência do turismo, entende que o processo e a coerência da teorologia não podem brotar dos estudos de caso, senão da confecção e refinamento dos paradigmas que orientam as investigações científicas.
} 


\section{TURISMO EM ANÁLISE}

que a realidade não tem substrato permanente e consiste - segundo eles - na relação dos fenômenos, que são o objeto do conhecimento humano.

\section{A Crise}

A teoria do turismo, se é que existe uma que se possa identificar como original - ou mesmo como "teoria DO turismo" (“do" em maiúsculas mesmo!) -, encontra-se em um momento crucial e delicado, pois existe uma crise e crítica do conhecimento de forma geral. A visão não é de pessimismo, mas de realidade. Os 4 momentos principais da crise, que foram identificados neste estudo, são:

1. Crise da universidade

2. Crise na filosofia

3. Crise dos valores culturais, humanos, morais e éticos e

4. Crise dos valores históricos

\subsection{Crise da universidade}

A universidade, lugar de excelência da produção do conhecimento científico está em crise, como já apontava Santos (2004). Segundo este autor, a crise tem três aspectos:

a) A crise da hegemonia - a universidade não é mais hegemônica na produção do conhecimento.

b) A crise da legitimidade - a universidade deixa de ser uma "instituição consensual".

c) A crise institucional - resultado da contradição entre buscar seus valores e objetivos e a pressão por critérios de eficácia e de produtividade.

De acordo com as três crises acima e ainda na esteira do pensamento de Santos (2004), percebe-se que a crise universitária é também política e econômica, não somente acadêmica. Para o Estado, a universidade não é prioridade, o que leva à descapitalização do sistema de ensino superior público e consequente perda de autonomia universitária, resultando em crise institucional, perda de cérebros, decadência do ensino, pesquisa medíocre, etc. Esta crise 


\section{TURISMO EM ANÁLISE}

universitária é provável que se refletita em todas as áreas universitárias e campos de conhecimento, inclusive no turismo e temáticas afins.

Como exemplo está o fato de que tanto na Europa, como na Ibero América, vários governos estão elevando as taxas, ou preços, do ensino universitário, ainda que estejam suavizando essa elevação com a oferta de bolsas de estudos e financiamentos ao estudante, a fim que ele pague o custo real e não seja um privilegiado cuja formação pagam todos os cidadãos através dos impostos.

\subsection{Crise na Filosofia}

A crise filosófica tem a ver com a crise das ciências em geral. O que ocorre é uma desvalorização da filosofia, mas ela continua importante. ${ }^{8}$ A crise é a da razão, que hoje é alimentada pelo valor supremo da "técnica" (não se vê nada além da tecnologia que "muda" nossas vidas). Crê-se, de modo geral, que a técnica pode responder a todos os problemas. Mas isso não ocorre, pois o homem é feito também de valores humanos, idealistas, emotivos, filosóficos, que lhe são negados pela valorização extrema da razão utilitária. Isto significa um descrédito da filosofia.

Esta falta de visão, de dedicação, de "amor" ao conhecimento - valor supremo da filosofia leva o pensar rapidamente à esterilidade da criatividade, à falta da compreensão das teorias filosóficas; à falta de teorização, de pensamento crítico, profundo, coerente e lógico. Consequentemente, sua aplicação no mundo prático não ocorre. Os valores iluministas da reflexão, da razão e da lógica são olvidados, ou trocados, por valores menores do mundo, tais quais: a indiferença, a desfaçatez, o egoísmo e a alienação (PANOSSO NETTO, 2011).

\subsection{Crise dos valores culturais, humanos, morais e éticos}

Esta crise, diz-se, nasce na modernidade e chega até os dias atuais com força. A cultura tornase um produto para ser vendido; o ser humano perde seu valor como pessoa e vale somente o

\footnotetext{
${ }^{8}$ Alguns abusos de filósofos pós-modernos foram denunciados no livro Imposturas intelectuales, por Sokal e Bricmont (1999). O original deste livro é de 1998. O "caso Sokal", como ficou conhecido, origina-se na publicação do artigo "Transgressing the boundaries: towards a transformative hermeneutics of Quantun Gravity. Social Text, vol. 46-47, primavera-verão, 1996, p. 217-252. Porém, Sokal e Bricmont também foram "denunciados" por seus supostos abusos no livro Imposturas Científicas, coordenado por Baudouin Jurdant (2003).
} 


\section{TURISMO EM ANÁLISE}

que produz; a perda dos limites morais e éticos limita as relações humanas verdadeiras e dificulta o estabelecimento de vínculos criativos. Tudo passa a ser permitido, pois não há parâmetros claros estabelecidos e, quando existem, faz-se de conta que não são importantes. Isto ocorre não somente na sociedade civil, senão também nas autoridades governamentais e nas instituições públicas colegiadas, que dão um péssimo exemplo.

Tais elementos críticos já foram bem discutidos por Bermann (1986), que se debruçou a esmiuçar o termo, o significado e a crise da modernidade; e por Lipovetsky (2005), que brada que vivemos na "sociedade do vazio", ou "sociedade do espetáculo". Sobre isso, Trigo, também apresenta uma posição:

O desenvolvimento intelectual, material e social do ser humano não foi acompanhado de avanços correspondentes nas áreas de moral e ética. $\mathrm{O}$ progresso tecnológico não é para todos; as sociedades de bem-estar social não atingiram a maioria das pessoas e hoje enfrentam resistências, graças às crises estruturais mais recentes (2008-2009). As promessas de um mundo mais justo e feliz foram limitadas e não aplacaram os ódios étnicos, de classe, entre religiões e grupos que se fecham na estupidez de seus fundamentalismos, apegando-se a dogmas espúrios e negligenciando a possibilidade de uma crítica racional que favoreça as sociedades pluralistas e democráticas (TRIGO, 2011, p. 16).

Essa limitação se reflete nos estudos turísticos a partir do momento que se assume o turismo com um fenômeno puramente econômico e se esquece de que as relações sociais, culturais, ambientais, etc., são fatores fundantes deste mesmo fenômeno. A visão estreita, de que o turismo é puramente economia, é um limitador no desenvolvimento das teorias atuais e na própria prática de um turismo mais justo e responsável.

\subsection{Perda dos valores históricos}

Em poucas áreas do conhecimento humano se observa tamanha falta de visão histórica do conhecimento produzido quanto na área do turismo. Percebe-se a carência de referência aos clássicos do turismo da década de 1930, e até mais anteriores, nos estudos publicados atualmente. Conforme apontam Panosso Netto e Tomillo Noguero (2011), as obras de GuyerFreuler (1874), Damm-Etienne (1910), Schullern zu Schrattenhofen (1911), Stradner (1917), 


\section{TURISMO EM ANÁLISE}

Mariotti (1923), Morgenroth (1927), Grünthal (1934), Glücksmann (1935), Poser (1939) e outros estudos já identificados, que vão da segunda metade do século XIX até princípios da II Guerra Mundial, não estão sendo considerados na atualidade ${ }^{9}$.

Os pesquisadores em turismo parecem não considerar os tempos históricos - geográfico, social e individual - que já dizia Braudel $^{10}$ (1995 [1949]); talvez por falta de conhecimentos, talvez por ignorância, talvez por desprezo. Não há um corpo teórico de conhecimentos que se configure como uma linha de saberes que avança ou que se refaz após refutações (não importa se o fundamento aqui seja Kuhniano ou Popperiano). Isso tudo leva a crer que estamos tornando-nos a-históricos, pois o que foi escrito ontem, parece não importar.

Os primeiros documentos referentes ao conhecimento técnico-científico-filosófico em turismo começaram a ser produzidos, de forma esporádica, na Itália, Suíça, Áustria e Alemanha, na primeira metade do século XIX e ganharam corpo antes mesmo de 1900. Essa visão vai contra a posição dos autores atuais de dizer que o conhecimento turístico foi criado pouco antes da Segunda Guerra Mundial, por volta da década de 1930.

Com essa lacuna na história, ou falta de memória coletiva em turismo, não ocorre o acúmulo de conhecimentos, não há espaço para a crítica e para a análise e a todo o momento são divulgados eventos como sendo o "primeiro congresso de turismo de-do-sobre...", vejam-se os exemplos:

- Não há relatos ou estudos sobre os primeiros congressos de turismo, tal como os que ocorreram em Graz, no Império Austro-Húngaro, cidade que hoje pertence à Áustria, em abril de 1884, e em setembro de 1894 (Panosso Netto e Tomillo Noguero, 2011).

- Sequer há uma "revisita" ou mesmo uma "visita" aos estudos de economia do turismo de Angelo Mariotti, que introduziu a disciplina economia do turismo na Universidade de Roma no período de 1925 a 1929.

\footnotetext{
${ }^{9}$ Exceção seja feita à excelente obra organizada por Dann e Parrinello (2009).

${ }^{10}$ Fernand Braudel é autor da clássica obra "O Mediterrâneo e o mundo Mediterrâneo na época de Filipe II" (1949). Nesta obra, sua tese de doutoramento defendida em 1947, apresenta uma nova concepção do tempo histórico, criada a partir de suas próprias investigações. Em sua teoria o tempo histórico está dividido e três ritmos: 1) um ritmo quase imóvel - geográfico - vindo das relações dos homens com o seu ambiente; 2) um ritmo lento - social - originado das relações das sociedades, dos estados, das economias, das civilizações; 3) um ritmo tradicional- individual - originado nos acontecimentos individuais.
} 


\section{TURISMO EM ANÁLISE}

- Falta releitura do célebre texto de Schullern zu Schrattenhofen (1911), que viu o turismo como fenômeno social, apontando e discutindo não só sobre seus inúmeros impactos positivos (que já eram bem conhecidos), mas também sobre seus impactos negativos, inclusive sociais.

- $\quad$ Não há uma discussão sobre a obra de Glücksmann (1917, 1935, por exemplo) que buscava a criação de "uma ciência turística" por meio de seu "esquema das causas do turismo" (GLÜCKSMANN, 1935, p. 12), inclusive amparado por seus colegas de trabalho e colaboradores do Forschungsinstituts für den Fremdenverkehr (Instituto de Pesquisa para o Turismo) de Berlim, entre eles os esquecidos Maximilian Klafkowski e Adolf Grünthal.

A lista de "esquecimentos" poderia ser mais longa, se assim fosse necessário. Aliás, toda a discussão sobre o estudo do turismo ser ou não ser uma ciência, já era discutido por Glücksmann (1935) e seu grupo. Infelizmente, alguns pesquisadores atuais, um pouco desavisados, acreditam que essa discussão surgiu no turismo com os estudos de Neil Leiper (1979) e Jafar Jafari (1994), ou até mesmo com publicações mais recentes, como a de Tribe (1997).

Os problemas apontados também se refletem, em maior ou menor grau, em outras áreas, porém, no turismo, eles aumentam, pois estão sob as lentes de outros problemas específicos, tais como:

- Indefinições conceituais - a área, por pura deficiência de seus investigadores, apresenta uma confusão de termos que não são padronizados e dependem da realidade em que estão sendo aplicados. Assim, no idioma alemão, não é possível falar em "turismo rural", pois a modalidade não existe nos padrões que foi desenvolvida no Brasil, por exemplo. Já o termo "turismo de habitação" será bem aplicado em Portugal, mas não no Brasil, pois o conceito, ao transpor o Atlântico, modifica sua semântica.

- $\quad$ Fragmentação do conhecimento produzido - por trabalharem de forma isolada, mesmo dentro de seus grupos de pesquisa, e por focaram suas investigações somente a partir de uma disciplina principal (economia, estatística, por exemplo), os pesquisadores fragmentam e não criam pontes entre os saberes turísticos produzidos. 


\section{TURISMO EM ANÁLISE}

Preconceito de pesquisadores de outros campos de estudo - mesmo sendo velado, existe certo preconceito e desprezo de pesquisadores de outras áreas, que são consideradas mais fundamentais. Parece ser vergonhoso se preocupar em estudar o turismo e todos os elementos relacionados a ele, tais como o entretenimento, a recreação, o lazer, o tempo livre, o ócio, etc.

- $\quad$ Sem historicidade - conforme apresentado anteriormente, a curta memória e a falta de retomada dos estudos antigos de turismo leva a criar "um campo de estudos sem passado", como se todo o conhecimento turístico fosse novo, atual.

- $\quad$ Fraqueza na sustentação de argumentos - os problemas e fraquezas destacados levam à formação de pesquisadores e de profissionais a terem uma fundamentação teórica baixa e pobre. Com essas características não é possível a abstração para a criação de argumentos práticos e teóricos sustentáveis.

\section{Outras Relações}

Um argumento contrário ao que aqui está exposto pode ser o que de "isso é muito teórico" ou de que "a teoria na prática é outra", etc. Somente os de formação teórica pobre podem ter este argumento, pois os problemas teóricos do turismo, que não são poucos conforme apontado anteriormente, podem se refletir na resolução das questões práticas da área.

Exemplo disso é a necessidade do turismo ser de fato autossustentável, em suas várias vertentes (cultural, ambiental, social, econômica). Como saber se é ou não autossustentável se não houver um estudo teórico?

Além do problema da sustentabilidade, que sem a ajuda da teoria não será respondido, ainda existem outros inúmeros problemas que se colocam "ao turismo prático" e que esperam abordagens teóricas consistentes para serem solucionados, tais como: ser mais acessível (em todos os sentidos); ser inclusivo; ser ético; ser mais humano e menos comercial; ser inovador; ajudar na redução do aquecimento global; superar os problemas do turismo de massa; transpor os problemas da super segmentação dos mercados; modelos de governança; entre outros. 


\section{TURISMO EM ANÁLISE}

Dos problemas práticos colocados, ainda surgem outros, como bem apontou Holden (2011), que se colocam como novos temas que clamam por soluções e que preocupam os cientistas sociais do turismo:

- O reconhecimento do valor do paradigma interpretativo e abordagens participativas nas pesquisas em turismo;

- Pluralidade de vozes - um movimento para além do mundo anglo-saxão;

- Conceitualização dos temas de "identidade", “cidadania" e "mobilidade";

- Pluralidade de publicações - reconhecimento da pesquisa em turismo pelas ciências sociais no mundo que não fala o idioma inglês;

- Hegemonia e poder;

- Turismo responsável, aviação, financiamento de micro negócios;

- Gestão ética ambiental, imperialismo ecológico;

- Economia verde e desenvolvimento sustentável;

- Filantropia e turismo voluntariado;

- Millennium Development Goals (MDG's - veja http://www.un.org/millenniumgoals/), redução da pobreza, gênero, Sustainable Tourism for Eliminating Poverty - ST-EP (veja http://www.unwtostep.org/);

- Direitos iguais em turismo: emprego, gênero, turismo gay, racismo, turismo social;

- Bem estar e saúde, turismo médico;

- Destravar o processo da dualidade do turismo:

Lutar contra a pobreza ou divulgar uma economia desigual.

Destruir a cultura ou renovar o orgulho cultural.

Natureza destrutiva ou ferramenta de conservação.

Escapismo ou autenticidade. 


\section{TURISMO EM ANÁLISE}

Empoderamento feminino ou exploração.

Portanto, a universidade seria (é?) o lugar privilegiado para a solução de tal imbróglio teórico e prático. Por ser o lugar do pensamento crítico, também deveria ser o lugar da criatividade; o lugar da imaginação, do entusiasmo; o lugar da liberdade de ação, da atuação, da reflexão; o lugar do intelectual; o lugar em que há que há espaço para a transgressão; o lugar do diferente, do novo, do excepcional, do maravilhoso, do admirável; o lugar que olhando para fora de si, pode oferecer uma resposta à sociedade e aos seus problemas.

Deve-se, então, neste espaço privilegiado, buscar a pesquisa engajada, não aquela que só serve para uma linha do Currículo Lattes (http://lattes.cnpq.br/ - é o sistema oficial de currículos do Brasil). Deve-se, ali, formar alunos que tenham senso crítico, criatividade, capacidade de trabalho em grupo, ética e possibilidade de inovação. Seria o espaço da Serendipity $^{11}$. A universidade operacional, que treina e adestra, deve ser rejeitada. É fato que grande parte dos conhecimentos acadêmicos, adquiridos na universidade, não será mais válida quando dela o estudante sair. Daí é que está a importância da visão crítica e não somente da formação técnica. Por certo, a formação técnica também é fundamental, necessária e bem vinda, mas em outro ambiente de ensino, não na universidade.

Neste sentido, o desenvolvimento de estudos críticos é valor fundamental para recolocar o turismo e o próprio ser humano no centro do debate, no intuito de reconduzir esse campo intelectual para uma perspectiva mais humana, solidária, sustentável, inclusiva dos grupos minoritários (indígenas, seringueiros e ciganos, por exemplo) ou que seja igualitário entre os gêneros.

\section{Ser Crítico}

A proposta da Teoria Crítica como paradigma de investigação tem suas mais fortes origens na Escola de Frankfurt, com Walter Benjamin, Theodor Adorno, Herbert Marcuse, Max Horkheimer e, mais recentemente, com Jürgen Habermas. Trata-se de uma rejeição ao

\footnotetext{
${ }^{11} \mathrm{O}$ termo refere-se a uma grata descoberta. Encontra-se algo positivo, que não se buscava, por caminhos adversos.
} 


\section{TURISMO EM ANÁLISE}

positivismo e a todas as suas dicotomias, clamando por um engajamento do intelectual com a sua realidade e problemas mais próximos.

Além disso, a Teoria Crítica estará preocupada com as relações de poder e admite a influência do pesquisador na coisa pesquisada - fato que o positivismo nega. A Teoria Crítica assume que valores morais e sociais interferem na maneira de pensar e na forma de construir conhecimentos.

Ser crítico é perceber que a pesquisa pode estar (e está), influenciada por grupos de poder. Pode ser o poder da agência financiadora da investigação, da universidade, dos pré-conceitos e pré-conhecimentos do investigador, do meio social, do objeto pesquisado, do governo, etc. Um dos papéis da Teoria Crítica, portanto, é desnudar e mostrar que há inúmeros interesses que estão relacionados com os fins e com os resultados finais de qualquer investigação.

As investigações também estão envoltas em ideologias, mas como as ideologias são amplas e se manifestam nos atos mais simples do dia-a-dia, age-se como se não estivesse sendo influenciado. Ser crítico, neste sentido, é buscar desvelar esta ideologia, escancarar seus objetivos, suas origens e permitir um pensamento o mais livre possível de vieses ideológicos.

Assim, ao se propor a construção de conhecimentos críticos, muito mais do que fazer a crítica ao conhecimento, deve-se saber distinguir entre o que é crítica e o que não é crítica, tal como apresenta Castillo Nechar (2011):

Não é crítica:

- $\quad$ Controvérsia, um desentendimento entre duas visões;

- $\quad$ Gosto que envolve preferências pessoais;

- $\quad$ Atitude de uso diário, como expressão dos defeitos de algo.

É crítica:

Ter a capacidade de discernir;

Cultivar um pensamento reflexivo interpretativo e abrangente; 


\section{TURISMO EM ANÁLISE}

- $\quad$ É uma postura intelectual que tenta analisar e avaliar a estrutura e a coerência do raciocínio.

Além da postura crítica proposta acima por Castillo Nechar (2011), as conclusões do estudo de Holden (2011) propõem outras ações práticas e teóricas, sendo elas (com adaptações dos autores):

- $\quad$ Buscar enfoques reconhecíveis, métodos e premissas na investigação em turismo;

- $\quad$ Avançar no desenvolvimento da plataforma de conhecimento de Jafar Jafari (1994);

- Revisar paradigmas e metodologias - proposta de "uma virada crítica" (ATELJEVIC, PRITCHARD e MORGAN, 2007);

- $\quad$ Definir o papel dos acadêmicos do turismo dentro e fora da comunidade acadêmica;

- Desenvolver teoria do turismo que envolva e seja relevante para a sociedade;

- $\quad$ Comunicar as descobertas a públicos diferentes, incluindo os agentes de poder;

- $\quad$ Encorajar a pluralidade de vozes e a investigação;

- $\quad$ Avançar no ambiente do ensino superior.

Castillo Nechar (2011, s.p.), sugere, para o avanço da ciência em turismo, três ações:

1. Tirar a carga positivista da ciência que tem um interesse pragmático, mecânico-casual e funcionalista;

2. Reconhecer a concepção da ciência e da epistemologia que existe sobre a construção do conhecimento produzido;

3. Compreender o termo ciência, em sua dimensão ampla, a partir do vocábulo scientia. (Neste caso refere-se o autor à concepção de scientia como conhecimento, prática, doutrina e erudição).

Uma reflexão pode ser feita sobre os investigadores de turismo brasileiros ao perguntar até que ponto as suas investigações podem ser transpostas para outras realidades? Podem ser úteis para outros pesquisadores os resultados publicados por autores brasileiros? Pesquisadores brasileiros estão "antenados" com as publicações da área - em outros idiomas - ou só se vê o 


\section{TURISMO EM ANÁLISE}

que está em português? O que se faz no Brasil, na universidade, é, de fato, pesquisa turística crítica? Etc.

Desta forma, para construir tal conhecimento crítico nos estudos turísticos, será necessário basear-se nos valores e alicerces da Filosofia e da Epistemologia, caso contrário o conhecimento pouco avançará e ficará limitado às vontades e desejos de grupos "proprietários" do conhecimento turístico. Será um conhecimento raso e sem fundamentos que se sustentem.

Portanto: "talvez o rei esteja nu!" Mas, sem filosofia e sem crítica, pode ser que não se descubra isso.

\section{Considerações Finais}

O artigo discutiu a importância dos estudos críticos para a construção de uma teoria sólida do turismo, condição fundamental para o desenvolvimento das pesquisas no campo prático. Estas pesquisas buscam alcançar, senão o status de "cientificidade", a utilização de métodos predominantemente quantitativos, mas que não podem avançar sem esse supedâneo representado pela teoria e pelo conhecimento. Devem estar firmemente alicerçados na epistemologia e na filosofia, sendo por essa razão que seus argumentos e conclusões desmoronam com facilidade, e não chegam a alcançar o grau de respeitabilidade tão cobiçado entre as chamadas áreas "duras" ou "científicas" do conhecimento.

Espera-se que a leitura dessas páginas dêem também margem à reflexão - e a possíveis mudanças, que somente nascem da reflexão - de que, em tempos de globalização, há a hegemonia de uma única ordem econômica, política e cultural, baseada no estilo de vida capitalista ocidental (notadamente o estadunidense, mesmo se se considerar a emergência da China, que possui sua economia e cada vez mais seus costumes fundados também no capitalismo ocidental), cujo poder se manifesta por meio do discurso. Deste modo, é corolário que as populações dos países situados às margens desse sistema global tomem a dianteira na produção de pensamentos e de discursos e, por conseguinte, apropriem-se de uma parcela 


\section{TURISMO EM ANÁLISE}

maior de poder, que não pode ser obtido por meio do mero reproduzir e regurgitar do pensamento oriundo da corrente intelectual anglo-saxã.

Faz-se pertinente, mais do que nunca, questionar as relações de poder que inevitavelmente existem, inclusive no nível da produção de conhecimento em turismo. O poder e a liberdade que a atual ordem global confere, requerem um aumento por parte das classes e populações periféricas em sua habilidade de participar nesses processos de construção. A chave que pode desatar este nó teórico possui duas etapas: embasamento filosófico sólido para, em seguida, propiciar a ação com visão crítica.

\section{Referências}

APOSTOLOPOULOS, Yiorgos. Introduction. Reinventing the sociology of tourism. In: APOSTOLOPOULOS, Yiorgos; LEIVADI, Stella. YIANNAKIS, Andrew. (Eds.) The sociology of tourism: theoretical and empirical investigations. New York: Routledge, 2005, p. 1-12.

ATELJEVIC, Irena; PRITCHARD, Annette, MORGAN, Nigel. (Eds.). Critical turn in tourism studies. Innovative Research Methodologies. Oxford: Elsevier, 2007.

BAUDRILLARD, Jean. Le systeme des objets. La consommation des signes. Paris: Denoel - Gonthier, 1972.

BAUDRILLARD, Jean. Simulacres et simulation. Paris: Éditions Galileé, 1981.

BERMANN, Marshall. Tudo que é sólido desmancha no ar. A aventura da modernidade. São Paulo: Companhia das Letras, 1986.

BORMANN, Artur. Die Lehre vom Fremdenverkehr. Berlin: Verlag der Verkehrswissenschaftlichen Lehrmittelgesellschaft m.b.H. bei der Deutschen Reichsbahn, 1931.

BOURDIEU, Pierre. La distinction: critique sociale du jugement. Paris: Minuir, 1979.

BRAUDEL, Fernand. O Mediterrâneo e o mundo Mediterrâneo na época de Filipe II. São Paulo: Martins Fontes, 1984 [1949] (2 volumes).

BRUNER, E. Abraham Lincoln as authentic reproduction: a critique of Postmodernism. In: American Anthropologist, 96 (2), 1994, p. 397-415.

CASTILLO NECHAR, Marcelino; PANOSSO NETTO, Alexandre. Epistemología del turismo. Estudios críticos. México: Trillas, 2010.

CASTILLO NECHAR, Marcelino. Epistemologia crítica do turismo. O que é isso? In: I Seminário Internacional de Estudos Críticos em Turismo. Universidade Federal do Rio Grande do Norte. Natal, 24 e 25 de março de 2011. (Disponível em: http://escritur.blogspot.com, acesso em 09 de agosto de 2011)

CASTILLO NECHAR, Marcelino; LOZANO CORTÉS, Maribel. Apuntes para la investigación turística. Cozumel-Quintana Roo: Universidade de Quintana Roo, 2006. 


\section{TURISMO EM ANÁLISE}

COHEN, Eric. A phenomenology of tourist experiences. Sociology, 13, 1979, 179-201.

CONDE GAXIOLA, Napoleón. Hermenéutica dialéctica transformacional aplicada al turismo, el derecho y las ciencias sociales. México-DF: Instituto Politécnico Nacional, 2008.

DAMM-ETIENNE, Paul. Das hotelwesen. Leipzig: Druck und Verlag von B. G. Teubner, 1910.

DANN, Graham M. S. Anglophone hegemony in tourism studies today. Enlightening Tourism. A Pathmaking Journal, 01, 2011, p. 1-30. (Disponível em: http://uhu.es/publicaciones/ojs/index.php/et/article/viewFile/1017/1521).

DANN, Graham M. S.; PARRINELLO, Liebman (Eds.). The Sociology of Tourism: European Origins and Developments. Bradford: Emerald Press, 2009.

DURKHEIM, Émile. Les Règles de la Méthode Sociologique. New York: Free Press, 1938 [primeira edição de 1894].

DURKHEIM, Émile. Les Formes Élémentaires de la Vie Religieuse. London: Allen and Unwin, 1915, [primeira edição de 1912].

ECO, Umberto. Il costume di casa. Milão: Bompiani, 1973.

ECO, Umberto. Sette anni di desiderio. Milão: Bompiani, 1983.

ENZENSBERGER, Hans Magnus. Vergebliche Brandug der Ferne: Eine Theorie des Tourismus. In: Merkur, 126, agosto de 1958, p. 701-720.

FOUCAULT, Michael. Naissance de la clinique. Une archéologie du regard médical. Paris: Presses Universitaires de France, 1963.

GLÜCKSMANN, Robert. Allgemeine Fremdenverkehrskunde. Berna: Verlag von Stämpfli und Cie, 1935.

GLÜCKSMANN, Robert. Privatwirtschaftslehre des Hotelgewerbes. M. Paschke, 1917.

GRABURN, N. Tourism, the sacred journey. In: SMITH, Valene. (Ed). Hosts and Guests. The Anthropology of Tourism. Philadelphia: University of Pennsylvania Press, 1977, p. 17-31.

GRÜNTHAL, Adolf. Probleme der Fremdenverkehrsgeographie. Die Fremdenverkehrskarte als Mittel der Marktanalyse. Die geographische Bedingtheit des Fremdenverkehrs. Schriftenreihe des Forschundsinstitit fur den Fremdenverkehr, Heft Geschichte der Tourismusforschung. HandelsHochschule. Berlin: Selbstverlag, 1934.

GUYER-FREULER, Eduard. Das Hotelwesen der Gegenwart. Zürich, Orell Füssli, 1874.

HOLDEN, Andrew. Relevance and insights. The relationship of the social sciences with tourism studies. In: Advancing the Social Science of Tourism Conference. University of Surrey, 28 de junho a 01 de julho de 2011.

HOLLINSHEAD, Keith. The Truth about Texas: a naturalistic study of the construction of heritage. (Dissertação inédita), Texas A \& M University, USA, 1993.

HUIZINGA, Johan. Homo ludens: proeve eener bepaling van het spel-element der cultuur. Haarlem: H.D. Tjeenk Willink, 1938.

JAFARI, Jafar. La cientifizacion del turismo. In: Estudios y Perspectivas en Turismo, v. 3, n. 1, Buenos Aires, 1994, p. 7-36. 


\section{TURISMO EM ANÁLISE}

JURDANT, Baudouin (Coord.). Imposturas Científicas. Los malentendidos del caso Sokal. Madrid: Ediciones Cátedra, 2003.

KNEBEL, H. Soziologische Strukturwandlungen im Modernen Tourismus. Stuttgart: Ferdinand Enke Verlag, 1960.

LEIPER, Neil. The framework of tourism: towards a definition of tourism, tourist, and the tourist Industry. Annals of tourism research, v. 6, n. 4, p. 390-407, out./dez., 1979.

LETT, J. Ludic and liminoid aspects of charter yacht tourism in the Caribbean. Annals of Tourism Research, 10, 1983, p. 35-56.

LIPOVETSKY, Gilles. A era do vazio. São Paulo: Manole, 2005.

MACCANNELL, Dean. The Ethics of Sightseeing. Berkeley e Los Angeles: University of California Press, 2011.

MACCANNELL, Dean. The tourist: a new theory of the leisure class. Berkeley e Los Angeles: University of California Press, 1976.

MARCEL, Gabriel. Homo viator: prolégomènes à une métaphysique de l'espérance. Paris: Aubier, 1945.

MARIOTTI, Angelo. L'industria del forestiero in Italia: economia e politica del turismo. Bologna: Nicola Zanichelli, 1923.

MORGENROTH, Wilhelm. Fremdenverkehr. In: Handwörterbuch der Staatswissenschaften. Vol. 2. P. 394-409. Jena: Verlag von G. Fischer, 1927.

PANOSSO NETTO, Alexandre. Filosofia do turismo: teoria e epistemologia. 2.ed. São Paulo: Aleph, 2011.

PANOSSO NETTO, Alexandre; TOMILLO NOGUERO, Félix. O conhecimento do turismo. Fontes e desenvolvimento do século XIX à Segunda Guerra Mundial. Valladolid (Espanha): São Paulo (Brasil), 2011. (Inédito e com título provisório).

PIAGET, Jean. Introduction à l'épistémologie génétique. Tome I: La pensée mathématique. Paris: PUF, 1950.

PIAGET, Jean. Introduction à l'épistémologie génétique. Tome II: La pensée physique. Paris: PUF, 1950.

PIAGET, Jean. Introduction à l'épistémologie génétique. Tome III: La pensée biologique, la pensée psychologique et la pensée sociale. Paris: PUF, 1950.

PIAGET, Jean. Le Langage et la pensée chez l'enfant. Paris: Delachaux et Niestlé, 1923.

POSER, Hans. Geographische Studien über den Fremdenverkehr im Riesengebirge: Ein Beitrag zur geographischen Betrachtung des Fremdenverkehrs. Abhandlungen der Gesellschaft der Wissenschaften zu Göttingen. Math.-Physical, Klasse 3. Folge, Heft 20. Göttingen: Vandenhoeck \& Ruprecht, 1939.

SANTOS, Boaventura de Sousa. A Universidade no Século XXI: Para uma Reforma Democrática e Emancipatória da Universidade. $2004 \quad$ (Disponível http://www.ces.uc.pt/bss/documentos/auniversidadedosecXXI.pdf. Acesso em 08 de agosto de 2011).

SCHULLERN ZU SCHRATTENHOFEN, Hermann von. Fremdenverkehr und Volkswirkschaft. In: Jahrbücher für Nationalökonomie und Statistik. Vol. III, 42, 4. Pp: 433-491. Jena: G. Fischer, 1911. 


\section{TURISMO EM ANÁLISE}

SCHÜTZ, Alfred. Der sinnhafte Aufbau der sozialen Welt: eine Einleitung in die verstehende Soziologie. Viena: J. Springer, 1932.

SIMMEL, Georg. Exkurs über den Fremden. In: RAMMSTEDT, O. (Ed). Soziologie. Gesamtausgabe, vol. 11: 764-771, Frankfurt: Suhrkamp, 1992 [1908].

SOKAL, Alan. "Transgressing the boundaries: towards a transformative hermeneutics of Quantun Gravity”. In: Social Text, vol. 46-47, primavera-verão, 1996, p. 217-252.

SOKAL, Alan. BRICMONT, Jean. Imposturas intelectuales. Barcelona: Ediciones Paidós Ibérica, 1999.

STAFFORD, Jean. Study, analysis and critique of the paradigms of research in teorology (the science of tourism). Les paradigmes de la recherche en téorologie: étude, analyse et critique. Loisir et Societé, Society and Leisure. Vol. 8, n. 2. 1985, p. 549-560.

STRADNER, Joseph. Der Fremdenverkehr. Eine volkswirtschaftliche Studie. 2.ed. Graz: Leykam, 1917.

TOMILlO NOGUERO, Félix. Principios, fundamentos y leyes de la teoría turística. Madrid: Universidad Antonio de Nebrija, 2008.

TRIBE, J. The indiscipline of tourism. Annals of Tourism Research, 24, 638-657, 1997.

TRIBE, John. Critical Tourism: Rules and Resistance. In: ATELJEVIC, Irena; PRITCHARD, Annette, MORGAN, Nigel. (Eds.). Critical tourn in tourism studies. Innovative Research Methodologies. Oxford: Elsevier, 2007, p. 29-39.

TRIBE, John. Tribes, territories and networks in the tourism academy. Annals of Tourism Research, v. 37, n. 1, p. 7-33, 2010.

TRIGO, Luiz Gonzaga Godoi. Apresentação da Segunda Edição. In: PANOSSO NETTO, Alexandre. Filosofia do turismo: teoria e epistemologia. 2.ed. São Paulo: Aleph, 2011, p. 15-17.

URRY, J. The Tourist Gaze. Leisure and travel in contemporary societies. London: Sage, 1990.

VON WIESE, Leopold. Allgemeine Soziologie als Lehre von den Beziehungen und Beziehungsgebilden der Menschen. München: Duncker und Humblot, 1924.

VON WIESE, Leopold. Fremdenverkehr als zwischenmenschliche Beziehungen. In: Archiv für den Fremdenverkehr, 1 (1), 1930, p. 1-3.

VYGOTSKY, Lev Semionovich. Pedagogicheskaia psikhologia. Moscou: Rabotnik Prosveshchenia, 1926.

VYGOTSKY, Lev Semionovich. Umstvennoie razvitie detei $v$ protsesse obuchenia. MoscouLeningrado: Uchpedgiz, 1935.

\section{Recebido em: 26/08/2011}

Aprovado em: 07/10/2011 